\title{
Appropriateness of Non-Destructive Measures of Young Pine Tree Performance in Weeding Experiments
}

\author{
N.S. Eccles, J.L. Kritzinger ${ }^{1}$ and K.M. Little
}

Institute for Commercial Forestry Research, P.O. Box 204, Sabie, 1260, South Africa.

\section{SYNOPSIS}

The objective of this work was to compare several commonly used measures of tree performance in three commercially grown pine species (Pinus patula, $P$. taeda and $P$. elliottii) during the first growth season in a weeding experiment. Both tree mortality and above-ground tree biomass measures indicated that there was significant tree suppression by weeds for all three species. Using above-ground biomass as an absolute measure of tree performance it was clear that root collar diameter was far more sensitive to treatment effects than height. A derived index combining both height and root collar diameter was consistently the most closely correlated with above-ground biomass. Leaf: stem ratios were significantly different between the three species, and between different weed regimes.

\section{INTRODUCTION}

Weeds research in the context of commercial pine plantations can be categorised into applied and fundamental research (Wagner, 1993). In applied research, the principle objective is the elucidation of growth responses of pines to alternative management treatments (eg. Clason, 1984; Miller et al., 1991; Haywood, 1994) and in some instances, the extrapolation of these results to yield improvements using growth and yield models (eg. Lauer et al., 1993). The main objective of fundamental research on the other hand is to advance our understanding of the principles underlying the results observed in applied research, and to thereby facilitate more robust generalisations and extrapolation (Zutter et al., 1986 b). Despite the clear differences in objectives between applied and fundamental research, the experimental treatments and designs which form the platforms for these are all variants of a common theme. The principle experimental distinction lies in the nature of the measurements which are carried out.

In applied weed research, the ultimate measure of tree performance in response to any experimental treatment is yield at the end of rotation. Unfortunately, because of the long rotation length in pines, indirect "interim" measures of tree performance are the rule rather than the exception. To our knowledge, only one paper has to date reported on end of rotation yields (Clason, 1993). Arguably the most robust interim indices of relative tree performance are de-

${ }^{2}$ Corresponding Author structive measures such as above-ground biomass. The biggest disadvantage of these is that trees can only be measured once. This is undesirable in the context of field experiments where the cost of establishing enough trees to give a healthy sample size is large. Non-destructive measures such as height, root collar diameter (or ground line diameter), and diameter at breast height are by far the most commonly used measures of tree performance. Very often these are used to calculate derived individual tree variates which are usually some index of main stem volume (eg. Ruehle et al., 1984). Alternatively, they are combined with mortality frequencies into estimates such as stand basal area or volume. Mortality as an index of tree response is in itself worthy of comment. Treatments resulting in differences in survival will have serious implications in terms of both long-term yield, and of operations costs associated with blanking (Morris, 1995). It is therefore perhaps more informative to analyse mortality data as a separate variate rather than as a component of a compound variate. In general non-destructive interim measures of tree performance have a number of advantages. They allow repeated measures to be carried out and thereby facilitate interrogation of time series of tree performance. They are also very quick and require no specialised equipment. Finally they are measures which form the basis for many management yield models and therefore allow extrapolation.

Tree measures peculiar to fundamental weed research generally focus on three issues: measuring the effects of weed control treatments on the water relations of the trees; measuring the effects of the treatments on the nutritional budgets of the trees 
(eg. Sands and Nambiar, 1984; Carter et al., 1984; Yeiser and Barnett, 1991; Woods et al., 1992), and finally, measuring the effect of the treatments on light attenuation (eg. Zutter et al., 1986 b; Cannell and Grace, 1993). These measurements often require specialised equipment such as pressure bombs, infra-red gas analysers, porometers etc. (although this is not always the case, e.g. Zutter et al., 1986 b). Because the objective of these measures is to attempt to explain tree growth responses, they necessarily go hand in hand with one or more of the measures of tree performance discussed above.

It is therefore clear that measures of tree growth will form the corner-stone of any experimental initiative in pines, irrespective of the precise objectives of a research project. Given this, an understanding of the relative sensitivity of standard measures of tree growth to weed treatments is important. The objective of this paper was to compare several common measures of tree performance in three commercially grown pine species during the first growth season in a weeding experiment.

\section{METHODS}

The study was initiated in December 1995 as part of a series of trials investigating the impacts of weed control on tree performance at establishment of three species of pines (Pinus taeda, $P$. patula, and $P$. elliottii) in the Mpumalanga province. The experiment was located at an altitude of about $1000 \mathrm{~m}$ on the Bergvliet plantation $\left(025^{\circ} 004^{\prime} \mathrm{S}, 030^{\circ} 052 ' \mathrm{E}\right)$. Weed growth at the site was fairly vigorous, with the biomass (wet mass - dry mass) exceeding $0,2 \mathrm{~kg} / \mathrm{m}^{2}$ within a month, and peaking at the end of the weed season at $1,18 \mathrm{~kg} / \mathrm{m}^{2}$. The weed community comprised of mixed woody and herbaceous vegetation (dominant species being Solanum mauritanum, Setaria megaphylla and Paspalum sp.) The soil was a deep well-drained Inanda form (Soil classification working group, 1991) and the rainfall recorded on the site over the study period was $1716 \mathrm{~mm}$.

A 3x2 factorial treatment design was used where the factors were pine species (Pinus taeda, $P$. patula, and $P$. elliottii) and weed control (weedy and weedfree). Weed control in the weed-free plots was achieved with a paraquat $(3 / / \mathrm{ha})$ and two glyphosate $4 l / \mathrm{ha}$ ) applications using plastic cones to shield the trees. These were imposed onto plots of $7 \times 6$ trees of which the inner $5 \times 4$ were measured. The treatment plots were nested into four complete randomised blocks. Tree heights $(\mathrm{H})$ and root collar diameters (RCD) were measured monthly. These were then used to calculate a biomass index (BI) (Ruehle et al., 1984);

$$
B I=R C D^{2} . H
$$

(Equation 1)

and its natural logarithm.

Mortality was recorded and trees were scored for browsing. In September 1996 a destructive harvest of all measured trees was conducted. A subsample of five trees per plot was separated into leaf and stem fractions and these were weighed. The remaining trees were simply weighed. Above-ground tree wet mass provided a reference (or absolute) measure of tree performance.

The appropriateness of height, RCD, biomass index and the natural logarithm of biomass index as measures of tree performance were examined by determining the correlations between these at the time of harvesting, and above-ground wet mass. Other analyses were carried out using analysis of variance (ANOVA) at each measurement time. These ANOVA's were not followed by any multiple-comparison protocol as these are "entirely invalid for factorial experiments" (Perry, 1986). Weedy versus weedfree performance for height, root collar diameter, biomass index and the wet mass were compared for each of the species separately using pre-planned orthogonal contrasts (Genstat 5 Committee, 1987). Because of the binomial nature of the mortality and browsing scores, plot percentages were first arcsine transformed prior to analysis (Steel and Torrie, 1980). Trees which had been browsed were excluded from further analyses because browsing frequency was significantly higher (F-probability $<0,001$ ) in the weedfree treatments. In variates where noticeable departures from homogeneity of variances occurred, the data were log transformed prior to analysis. This was found to produce a satisfactory correction in all cases. All analyses were carried out using the Genstat statistical package.

\section{RESULTS AND DISCUSSION}

In terms of mortality, there was no significant interaction between weed control and species, and there was no significant species main effect. The probability that the variance attributable to the weeding treatments was statistically significant was 0,076 . We would therefore accept that the mean frequency of mortality in the weedy plots of $8 \%$ was significantly greater than the $1,7 \%$ mean in the weedfree plots at the $10 \%$ Type-I error level. At the time of harvesting, above-ground biomasses in the weedy treatments were significantly lower than in the weedfree treatments in all three species (F-probability $<0,001$ in all three species) (Figure 1). In the case of $P$. patula, the mean biomass in the weed-free treatment was $60,64 \mathrm{~g}$ as opposed to $19,82 \mathrm{~g}$ in the weedy plots. In $P$. taeda, the weed-free mean was $29,99 \mathrm{~g}$ as opposed to $10,72 \mathrm{~g}$, and in $P$. elliottii the treatment mean biomasses were $42,35 \mathrm{~g}$ and $8,8 \mathrm{~g}$ respectively for the weed-free and weedy treatments. From these results it is clear that competing vegetation resulted in dramatic tree suppression, and in some instances even mortality.

The correlations in Table 1 suggests that root collar diameter was a far better indicator of tree performance than height in all three pine species. This generalises similar findings in $P$. taeda during the equivalent establishment phase (Zutter et al., 1986 a and b). In the case of $P$. taeda it has been 
reported that this trend is sustained till at least the forth growth season (Bacon and Zedaker, 1987). However, the most useful non-destructive measures of tree performance in all species was the biomass index described in Equation 1, and its natural logarithm. The correlation coefficients between this index and biomass were consistently slightly superior to root collar diameter/biomass correlations (Table 1). The reason for this is that the biomass index combines both heights and root collar diameters into an integrated measure of tree performance which is closely related to the volume of the main stem. Volume is in turn linearly related to mass of the main stem. In addition, the correlations between the natural logarithms of the biomass index and the natural logarithms of biomasses were consistently the great-

Table 1. Correlations between the non-destructive measures of tree performance and above-ground biomass for three species of pine. $H$ is height, $R C D$ is root collar diameter, $B I$ is biomass index and $\operatorname{In}(B I)$ is the natural logarithm of biomass index

\begin{tabular}{|l|c|c|c|c|}
\hline & $\mathrm{H}$ & $\mathrm{RCD}$ & $\mathrm{BI}$ & $\operatorname{In}(\mathrm{BI})$ \\
\hline $\begin{array}{l}\text { P.patula } \\
\text { Biomass } \\
\text { In (biom.) }\end{array}$ & 0,475 & 0,903 & 0,925 & 0,857 \\
& 0,463 & 0,928 & 0,847 & 0,935 \\
\hline P.taeda & & & & \\
Biomass & 0,551 & 0,900 & 0,935 & 0,828 \\
In (biom.) & 0,595 & 0,934 & 0,822 & 0,953 \\
\hline P.elliotti & & & & \\
Biomass & 0,619 & 0,913 & 0,942 & 0,881 \\
In (biom.) & 0,638 & 0,928 & 0,858 & 0,964 \\
\hline
\end{tabular}

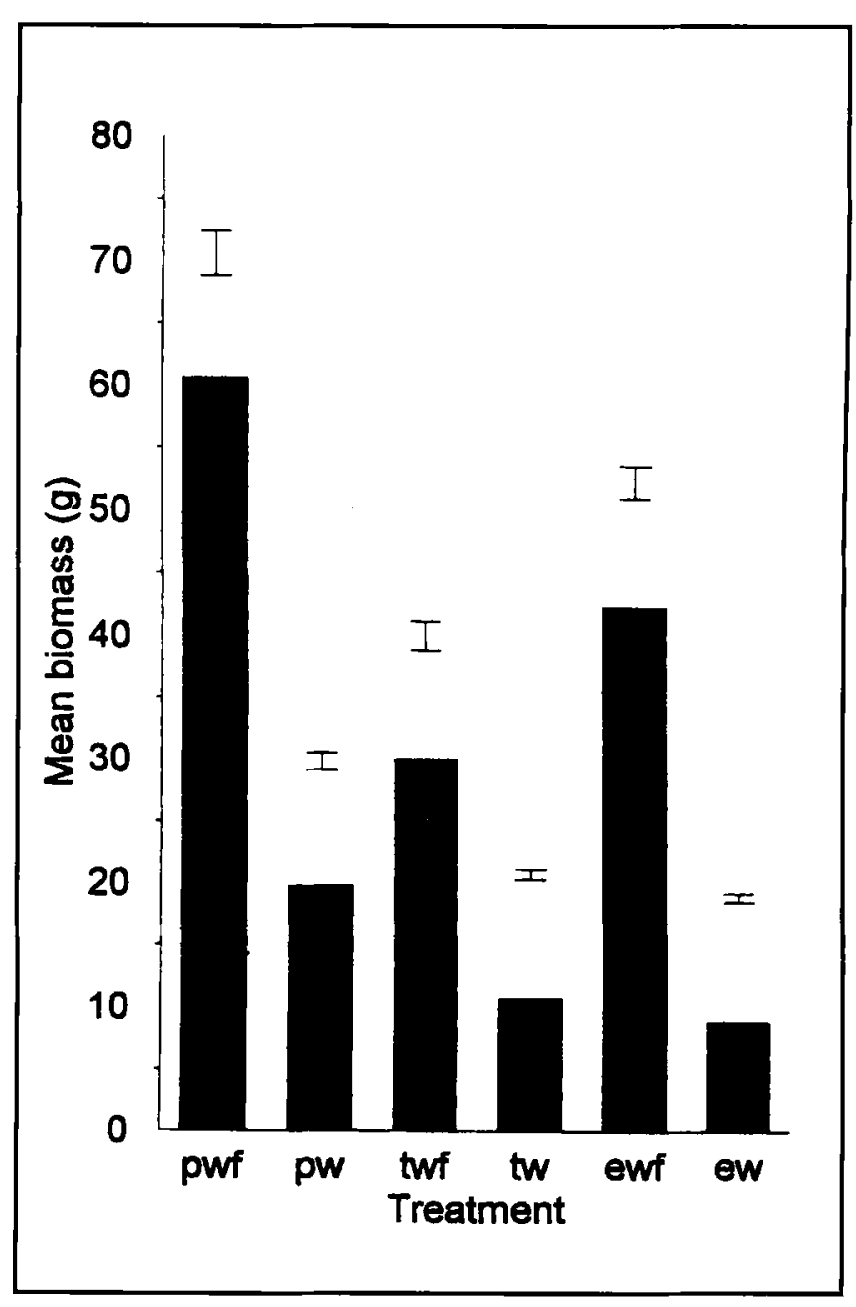

Figure 1. Mean above-ground biomasses for the different treatments at the time of harvesting. "pwf" is weed-free P.patula, "pw" is weedy P. patula, "tw" is weedy P. taeda, "ewf" is weedfree P.elliottii and finally, "ew" is weedy P.elliottii. The error bars represent the standard errors of the treatment means $(n=80)$

$T A B L E$ 2. Contrast probabilities of great $F$-statistics associated with the time series of means for heights, root collar diameters and the natural logarithm of biomass index

\begin{tabular}{|l|l|l|l|l|l|l|l|}
\hline & Jan & Feb & Mar & May & Jun & Jul & Aug \\
\hline HEIGHT & & & & & & & \\
\hline patula w vs. wf & 0,787 & 0,245 & 0,059 & 0,775 & 0,503 & 0,101 & 0,023 \\
taeda w vs. wf & 0,743 & 0,955 & 0,478 & 0,334 & 0,271 & 0,174 & 0,761 \\
elliotti w vs. wf & 0,529 & 0,431 & 0,486 & 0,173 & 0,208 & 0,010 & 0,007 \\
\hline RCD & & & & & & & \\
\hline patula w vs. wf & 0,878 & 0,867 & 0,517 & 0,037 & 0,001 & $<, 001$ & $<, 001$ \\
taeda w vs. wf & 0,788 & 0,745 & 0,052 & $<, 001$ & $<, 001$ & $<, 001$ & $<, 001$ \\
eliottii w vs. wf & 0,950 & 0,616 & 0,889 & $<, 001$ & $<, 001$ & $<, 001$ & $<, 001$ \\
\hline In(BI) & & & & & & & $<, 001$ \\
\hline patula w vs. wf & 0,764 & 0,791 & 0,266 & 0,089 & 0,003 & $<, 001$ \\
taeda w vs. wf & 0,758 & 0,161 & 0,030 & $<, 001$ & $<, 001$ & $<, 001$ & $<, 001$ \\
elliottii w vs. wf & 0,629 & 0,920 & 0,617 & $<, 001$ & $<, 001$ & $<, 001$ & $<, 001$ \\
\hline
\end{tabular}


est overall. Separating out the data from weedy and weed-free treatments and then examining the same correlations suggested precisely the same trend (data not shown). However, the correlations between height and biomass when viewed individually were generally stronger than when the data were pooled. The implication of this is that while in weeding experiments height is clearly a poor variate on its own, this effect is likely to be present (although weaker) in experiments investigating treatments other than weeding.

In terms of the time series of tree performance, the response to competing vegetation differed according to the variate analysed (Figure 2 and Table 2). In general, the differences between tree heights in the weedy and weed-free treatments for all of the species
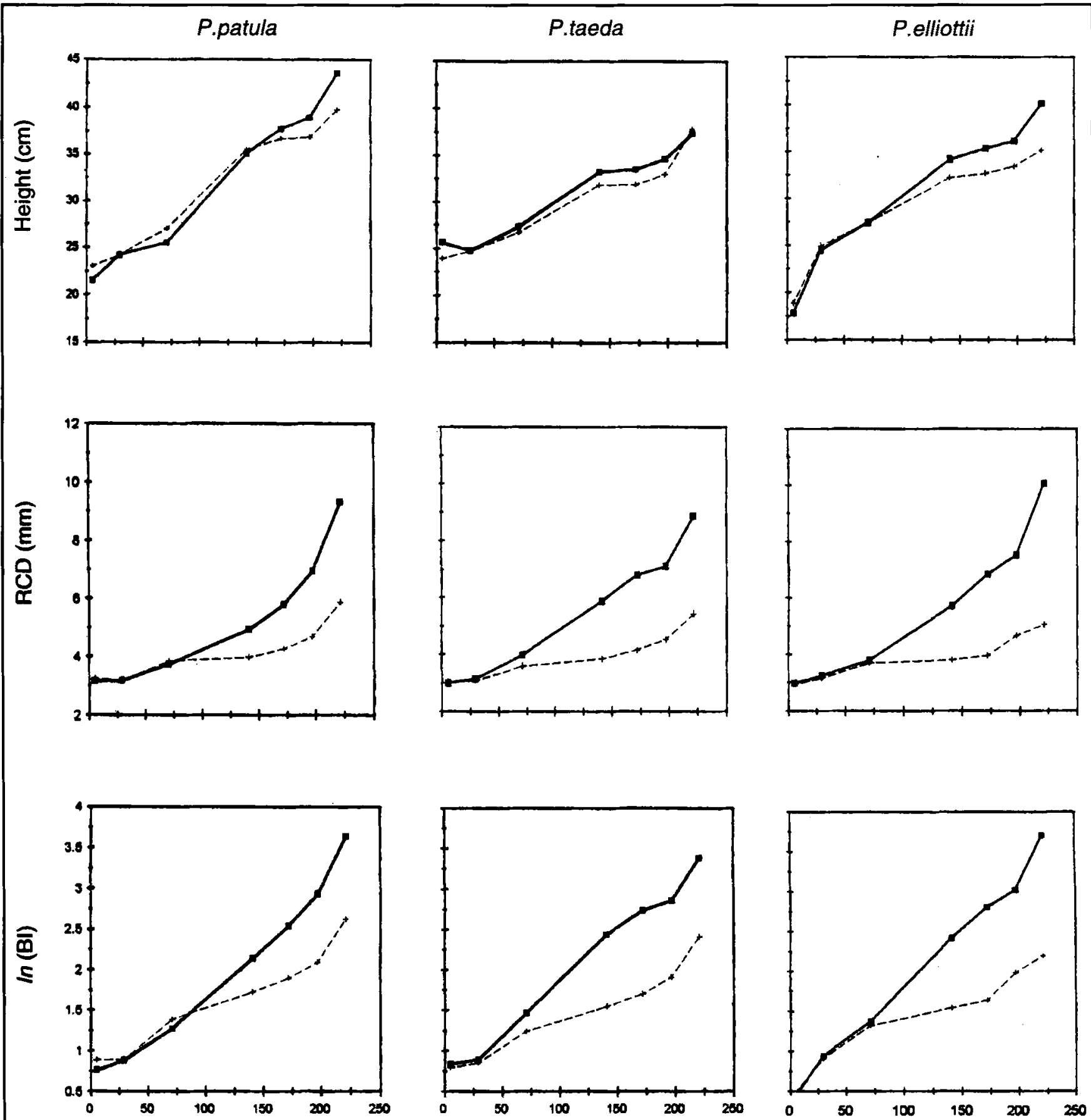

Time (days after planting)

--+-- Weedy

Weedfree

FIGURE 2. Time series of heights, root collar diameters (RCDs) and the natural logarithm of the biomass index (In[BI]) in three pine species 
were slight, although towards the end of the experimental period, the differences were statistically significant in both $P$. patula and $P$. elliotii (Table 2 ). In the case of root collar diameters and the natural logarithm of the biomass index, there was very noticeable tree suppression by the time of harvesting. This suppression was initiated between 71 and 140 days after establishment in $P$. elliotii and $P$. patula and perhaps slightly earlier in $P$. taeda (Figure 2 ).

One possible explanation for this difference in response between height and other measures of tree performance on this site is that, in the presence of competing vegetation, pines reallocated resources into growing upwards in an attempt to "escape" a shading effect (Holt, 1995). In addition, given this flexibility of resource allocation it is tempting to speculate that there may also have been changes in the allocation of biomass between leaves and stems. This was indeed found to be the case with statistically significant main effects for both the weed and species factors when the leaf:stem ratios were analysed ( $F$-probability $=0,003$ and $<0,001$ respectively). There was no significant interaction. In general, the trees in the weedy treatments had higher leaf:stem ratios than in trees in the weed-free plots $(1,159$ as opposed to 0,929 respectively). The existence of this flexible allocation is in line with the results in $P$. taeda described in Zutter et al., (1996 b), and in $P$. taeda and $P$. elliottii reported in Colbert et al., (1990). However, while the direction of allocation shift in response to weeds was consistent for all three species on this site, Zutter et al., (1986 b) reported no common trend across different sites. It is thus possible that the direction of allocation shift may be a good indicator of the relative importance of competition for above and below ground resources in pines on different sites. Of the three species, $P$. taeda had the highest leaf allocation with a mean leaf:stem ratio of 1,374 , followed by $P$. patula $(0,964)$ and then $P$. elliottii $(0,793)$.

To conclude, results from this experiment indicate that derived measures of tree growth which combine both height and root collar diameter are likely to be more closely related to tree biomass than either of the two direct measures. Of the two direct measures, root collar diameter was consistently superior to height in the context of a weeding experiment. In addition, the observed flexible resource allocation between height and girth growth, and between leaf and stem growth may provide a basis for assessing the relative importance of competition for different resources.

\section{ACKNOWLEDGEMENTS}

We would like to thank Rob Nkonde and Pat Thabethe for their assistance with various aspects of field work. We would also like to thank Sandy Freimond, Ross Allen and an anonymous referee for their com- ments on the draft manuscript. Finally, we would like to thank SAFCOL for supplying the experimental site.

\section{REFERENCES}

BACON, C.G., and ZEDAKER, S.M., 1987. Third-year growth response of loblolly pine to eight levels of competition control. South. J. Appl. For. 11: 91-95.

CANNELL, M.G.R., and GRACE, J., 1993. Competition for light: detection, measurement, and quantification. Can. J. For. Res. 23: 1969-1979.

CARTER, G.A., MILLER, J.H., DAVIS, D.E., and PATTERSON R.M., 1984. Effect of vegetative competition on the moisture and nutrient status of loblolly pine. Can. J. For. Res. 14:1-9.

CLASON, T.R., 1984. Hardwood eradication improves productivity of thinned loblolly pine stands. South. J. Appl. For. 8: 194197.

CLASON, T.R., 1993. Hardwood competition reduces loblolly pine plantation productivity. Can. J. For. Res. 23: 2133-2140

COLBERT, S.R., JOKELA, E.J., and NEARY, D.G., 1990. Effects of annual fertilisation and sustained weed control on dry matter partitioning, leaf area, and $g$ rowth efficiency in juvenile loblolly and slash pine. Forest Sci. 36(4): 995-1014.

GENSTAT 5 COMMITTEE, 1987. Genstat 5 Reference Manual. Oxford Scientific Publications, Oxford. pp. 426-433.

HAYWOOD, J.D., 1994. Tenth-year results of herbaceous weed control in a loblolly pine plantation. South. J. Appl. For. 18: 105-109.

HOLT, J.S., 1995. Plant responses to light: A potential tool for weed management. Weed Science. 43: 474-482.

LAUER, D.K., GLOVER, G.R., and GJERSTAD, D.H., 1993. Comparison of duration and method of herbaceous weed control on loblolly pine response through midrotation. Can. J. For. Res. 23:2116-2125.

MILLER, J.H., ZUTTER, B.R., ZEDAKER, S.M., EDWARDS, M.B., HAYWOOD, J.D, and NEWBOLD, R.A., 1991. A re gional study on the influence of woody and herbaceous competition on early loblolly pine growth. South. J. Appl. For. 15: 169-179.

MORRIS, A., 1995. Proposed weed management standards for reestablishment of pine pulpwood plantations in the Usutu forest. Usutu Pulp Company Forest Research Document. 4/95.

PERRY, J.N., 1986. Multiple-comparison procedures: A dissenting view. J. Econ. Entomol. 79: 1149-1155.

RUEHLE, J.E., MARX, D.H., and MUSE, H.D., 1984. Calculated nondestructive indices of growth response for young loblolly pine. Forest Sci. 30: 469-474.

SANDS, R., and NAMBIAR, E.K.S., 1984. Water relations of Pinus radiata in competition with weeds. Can. J. For. Res. 14: 233-237.

SOIL CLASSIFICATION WORKING GROUP, 1991. Soil classification. A taxonomic system for South Africa. Department of Agricultural Development, Pretoria.

STEEL, R.G.D., and TORRIE, J.H., 1980. Principles and Procedures of Statistics. A Biometrical Approach. 2nd Ed. McGrawHill Book Company, Aukland. pp. 233-237.

WAGNER, R.G., 1993. Research directions to advance forest vegetation management in North America. Can. J. For. Res. 23: 2317-2327.

WOODS, P.V., NAMBIAR, E.K.S., and SMETHURST, P.J., 1992 Effect of annual weeds on water and nitrogen availability to Pinus radiata trees in young plantations. Forest Ecology and Management. 48: 145-163.

YEISER, J.L., and BARNETT, J.P., 1991. Growth and physiological responses of four shortleaf pine families to herbicidal control of herbaceous competition. South. J. Appl. For. 15: 199. 204.

ZUTTER, B.R., GJERSTAD, D.H., and GLOVER, G.R., 1986 a Effects of herbaceous weed control using herbicides on a young loblolly pine plantation. Forest Sci. 32: 882-899.

ZUTTER, B.R., GJERSTAD, D.H., and GLOVER, G.R., 1986 b. Effects of interfering vegetation on biomass, fascicle morphology and leaf area of loblolly pine seedlings. Forest Sci. 32 . 1016-1031. 